\title{
Observations of Dominant Behaviors and Habits of an Effective Leader
}

\author{
Ron Drew Stone \\ President, Center for Performance and ROI, Pelham, AL, USA \\ Email: drewroi@aol.com
}

How to cite this paper: Stone, R. D. (2021). Observations of Dominant Behaviors and Habits of an Effective Leader. Open Journal of Social Sciences, 9, 490-497. https://doi.org/10.4236/jss.2021.910035

Received: October 15, 2021 Accepted: October 26, 2021

Published: October 29, 2021

\begin{abstract}
Leadership behavior is at the center of organization performance. Organizations dedicate significant resources to develop leaders so that work teams will achieve organization goals. Theories abound about the traits, characteristics and behaviors that make for the best leaders. Since team members and others who work closely with leaders are in a good position to know the answers, I asked these employees what type of leader and which leader behaviors influence them to do the work and stay connected with the organization. The research identified numerous behaviors and habits that facilitate communication, trust, respect, working relationships, and positive performance. These findings are arranged in two guides, each with an array of behaviors. One guide is for building leadership character and the other is for influencing connection conversations. Both guides are beneficial to leaders as they engage their team to achieve organization goals. A leadership workshop is forthcoming that focuses on applying the guides along with tools for leaders to connect with teams and achieve individual and organization performance goals.
\end{abstract}

\section{Keywords}

Connections, Respect, Trust, Leader, Behavior, Habits, Willingness, Character, Compassion, Performance

\section{Introduction to the Topic}

A wide range of internal and external factors contribute to employee performance and business outcomes of an organization. One of the key factors is leadership behavior. Regardless of job title, supervisor, foreman, team leader, manager, vice president, leaders have a profound impact on individual, team, and organization performance. The behavior of leaders affects the behavior of team members, which in turn plays a key role in influencing key business metrics. 
It is the responsibility of leaders to manage the people and processes to sustain and improve business outcomes. Leader behavior affects metrics such as employee productivity, quality of work, cost of work processes, employee satisfaction, absenteeism, attendance, turnover, customer service and many more business outcomes. Unfortunately, ineffective leader behavior and habits sometimes drive team behavior and business metrics in the wrong direction. Consequently, to get the most out of its resources and improve business outcomes, organizations expend significant dollars on leadership development for emerging and current leaders. According to a 2019 Forbes.com article, leadership development is a $\$ 366$ billion global industry (Westfall, 2019).

Leaders today are expected to focus a significant amount of their time and energy to facilitate employee and team performance with the end-in-mind being a productive balance between employee satisfaction and effective business outcomes. This two-part formula, employee satisfaction and business outcomes, is a complex relationship with no known secret sauce. Many scholars say: While one leadership approach may seem to work best with knowledge workers, another may seem to work with a field sales force, and yet another with factory workers, and another with a remote workforce, and so on. With so many variables at play in any performance situation, and there are many, it is difficult to discover cause and effect. While we can find evidence of cause and effect, absolute proof of the most effective leadership approach in any given situation is likely beyond our reach.

If we cannot prove cause and effect, why study leadership and why write about it? We continue our research because there is always something more to learn from meaningful research. Times do change, issues change, people change. We can discover and measure relationships and eliminate or include certain causal factors. More importantly, we can at least determine the key factors that make a difference when it comes to leadership behaviors and habits. The best way to discover the most effective behavior is to ask those who are most affected and influenced by leadership behavior. That is, those that work directly with and for the leader.

\section{Theories about Leadership from Other Authors}

Leadership is central to the operation of every organization. My paper focuses on the behavior of leaders, because my thorough research concludes that it's behavior that makes a difference. Regardless of leadership style or structure it is leader behavior that compels others to follow or not to follow. However, many writings focus on leadership theories and styles. A multitude of theories, principles and models are put forth by educational institutions, thought leaders, consultancies, and practitioners that strive to understand, teach, and guide about leadership styles. Books, articles, research papers, and internet rumble are too numerous to mention.

Many scholars and practitioners argue there is not one leadership style that works best, but it depends on numerous factors such as the nature of the work, how the work dictates relationships within teams and across teams, the problem 
solving and decision-making processes in play, and so on. A few theories by other authors are addressed here only to give a small sample of the range of thought about leadership.

\subsection{When Deciding How to Lead, the Situation Matters}

In the late sixties, Hersey, and Blanchard (1969) introduced the Situational Leadership theory which remains popular today. Paul Hersey and Ken Blanchard developed their leadership theory while writing about organizational behavior. Their model has been refined over the years and many subsequent books and articles are currently available on the topic. Hersey and Blanchard's model says the leadership style should be adjusted to adapt to each task or situation along with the needs of the performer. The model is based on four styles of leadership applied differently based upon task difficulty, the situation, and the performer's level of development.

\subsection{Empowering Employees Could Be a Positive Influence on Performance}

Empowering employees in the workplace is generally thought to be a means of achieving improved performance. It is based on the principle that leaders should support employees by providing them the authority, resources, and opportunity to accomplish the work and hold them accountable for the results. Lee, Willis, and Tian (2018) conducted a meta-analysis of 105 studies on empowerment with some interesting findings. One area they addressed is a comparison of empowerment in Eastern and Western cultures and the differences in impact.

\subsection{A Different Approach Could Influence Performance in Knowledge-Intensive Organizations}

A debate has ensued for many years about effective leadership styles in knowledge intensive organizations. Many have claimed that professionals are self-driven and therefore leadership is less important. Goodall and Baker (2014) studied effective leadership in knowledge intensive organizations. One area they addressed is whether the kind of leader makes a difference such as, experts and professionals being led by other experts.

\section{Purpose of My Leadership Study}

The purpose of my leadership study was to address observations of the most dominant behaviors and habits of effective leaders that influence employee ability and willingness to complete the work in the prescribed manner to achieve business outcomes.

\section{My Research Approach to Determine the Most Dominant Behaviors and Habits of Effective Leaders}

The research for this study employed a thematic and sentiment analysis of qua- 
litative data from an open-ended twelve question customized survey and virtual interviews. Two focus groups were conducted for the purpose of determining the questions that would be asked on the survey. The survey asked $968 \mathrm{em}$ ployees to elaborate and give examples in answering each question about leadership behavior and habits. Eighty-four virtual interviews followed the same questioning pattern. The questions solicited responses about the types of leadership behavior that influence positive outcomes with team members, leader behavior that makes a team member feel valued and relevant, leader behavior that leads to negative results, and other leadership factors affecting performance. Table 1 includes a summary of the methodology, timing, and sources for the study.

The survey used to collect data in this study employed only open-ended questions. The responses were plentiful and detailed, which indicated a strong desire to communicate about leadership issues. With a total of 7630 qualitative written responses, five-months were required to thoroughly analyze the data. As an author and practicing consultant, I have conducted over 700 business impact studies around the globe during the past twenty-five years. I have also coached my clients as they conducted many additional studies. I know the difficulty of getting people to respond to surveys of all types, particularly with open-ended questions. I was encouraged and impressed by the overwhelming response and the quality of the responses to a survey that was exclusively open-ended questions.

Table 1. Research methodology, timing, methods, and sources of the research.

\begin{tabular}{|c|c|c|}
\hline Item & Leadership Survey & Leadership Interviews \\
\hline Timing & Jan. 2018 through March 2020 & Oct. 2018, through Dec. 2020 \\
\hline $\begin{array}{l}\text { Countries and } \\
\text { Areas included in } \\
\text { the Study }\end{array}$ & $\begin{array}{l}\text { USA, China, India, Malaysia, Thailand, UK, } \\
\text { Hong Kong, Canada, Japan, South Korea, } \\
\text { South Africa, Australia, and Singapore. }\end{array}$ & $\begin{array}{l}\text { USA, China, India, Malaysia, Hong } \\
\text { Kong, Thailand, UK, South Korea, } \\
\text { Puerto Rico, Ireland }\end{array}$ \\
\hline $\begin{array}{l}\text { Data Collection } \\
\text { Methods }\end{array}$ & $\begin{array}{l}\text { Customized qualitative survey: Twelve } \\
\text { open-ended questions administered online to } \\
986 \text { employees over 2-year 3-month period. }\end{array}$ & $\begin{array}{l}\text { Conducted virtual interviews. Same } \\
\text { twelve questions as survey with the } \\
\text { addition of follow-up capability. }\end{array}$ \\
\hline $\begin{array}{l}\text { Data Collection } \\
\text { Sources }\end{array}$ & $\begin{array}{l}968 \text { sources targeted representing all job levels. } \\
640 \text { responded }(66 \%) \text {. } \\
\text { - } 38 \text { upper-level management leaders }(6 \%) \text {. } \\
\text { - } 70 \text { mid-level management leaders }(11 \%) \text {. } \\
\text { - } 147 \text { first-line management }(23 \%) . \\
\text { - } 385 \text { non leadership positions }(60 \%) \text {. } \\
\text { Employed by } 97 \text { unrelated organizations in } 26 \\
\text { types of businesses/agencies, including private } \\
\text { industry, government, higher education, and } \\
\text { non-profits. Anonymity was promised. }\end{array}$ & $\begin{array}{l}100 \text { targeted, } 84 \text { interviews } \\
\text { completed }(84 \%) \text {. } \\
\text { - } 7 \text { upper-level management leaders } \\
(8 \%) . \\
\text { - } 10 \text { mid-level management leaders } \\
(12 \%) . \\
\text { - } 19 \text { first-line management leaders } \\
(23 \%) . \\
\text { - } 48 \text { in non-leadership positions } \\
\quad(57 \%) . \\
\text { Employed by } 18 \text { unrelated } \\
\text { organizations in } 12 \text { types of } \\
\text { businesses/agencies, including } \\
\text { private industry, government, higher } \\
\text { education, and non-profits. } \\
\text { Anonymity was promised. }\end{array}$ \\
\hline
\end{tabular}


All survey questions were asked in the context of "the most effective leader" and respondents were encouraged to elaborate on their answers. As an example, a question was framed like this. "What are the top 3 to 5 behaviors or habits your most effective leaders have demonstrated that impacted your performance in a positive way?" The interviews followed the same pattern as the survey but afforded the opportunity to ask follow-up questions and dig deeper into responses and issues. Interviewees were very engaged during the interviews. Eleven of the interviews were cut short by the interviewee due to business interruptions. However, in each case, the interviewee scheduled a time to reconnect and finish the interview. Questions a) through j) were asked in the same context as the above example. The most effective leader behaviors:

a) that influence your willingness to follow a specific leader.

b) that make you feel valued and relevant.

c) that impact your job performance in a positive way (same Q but behaviors that impact negatively).

d) during conversations about performance expectations.

e) during ongoing "check-in" performance progress conversations.

f) when the leader observes positive performance results (same Q but when expectations not met).

g) in managing the work, itself.

h) that facilitate positive relationships among team members.

i) that facilitate individual development and growth.

j) when the team is experiencing significant change or crisis.

\section{Survey and Interview Research Results on Dominant Behaviors and Habits of Effective Leaders}

Consolidated survey and interview results are listed below with a couple of the most dominant responses. For brevity, only three key results are listed. The first two result areas, "connection" and "respect and trust," received almost the same number of responses and elaboration.

\subsection{Research Results: Leader Behavior that Initiates and Sustains Connections with Teams and Team Members (1650 Responses)}

Employees consider conversation connections of highest importance. The most significant behavior a leader can demonstrate is to take actions to connect with and engage team members. Connection establishes a path to develop relationships to further build understanding and trust not just for the leader and individual team members, but for the entire team. Leader connection is about initiating contact, asking questions, listening, and engaging more so than talking. Connection is not a one-time deal, it is ongoing. When there is no connection, some team members may be reluctant to speak out, may not feel valued, and may even feel isolated and disengage from the team. When team members become disengaged, the negative ramifications on productivity, work quality and 
customer services are significant. Disengagement of a team member also affects other team members and their ability to stay on task and do their best.

Recognition was mentioned a substantial number of times as one of the most valued leader connection behaviors. A significant amount of feedback noted that leaders who can bring clarity to performance expectations and manage those expectations alongside team member relationships and pressing work priorities are highly valued. The feedback also informs us that the team members that meet expectations with "good or average performance" are usually the ones responsible for meeting goals and keeping customers happy, and not those few who excel. Leaders that acknowledge this are high on the list of valued leaders. A substantial amount of feedback addressed how leaders need to start over at ground zero and learn how to recognize good, not great, performance. As several respondents noted, praise encourages development.

This research informs us that leader connection with team members includes many factors ranging from; performance expectations, to growth and development, to recognition, to managing the work itself, to managing a bad day. These and other connection factors have been captured as Nine Key Conversations to initiate and sustain connection. They are addressed at the end of this paper.

\subsection{Research Results: Leader Behavior That Develops Respect and Trust within Teams and with Individual Team Members (1576 Responses)}

The research is dominant with mention and elaboration of respect and trust. As stated earlier, there is as much feedback about respect and trust as there is about connection. Team members expect their leader to be fair, truthful, equitable, and have moral fiber and integrity. Among the leader behaviors mentioned most valued in the feedback that develop respect and trust are:

- Keep commitments to the team. Say what you mean, mean what you say.

- Respect implications of change on the team and on individuals. Tell us the truth as you know it and reassure us on how we will be affected. Help us find stability where it exists and help us adapt.

- Advocate for your team. Go to bat for us in every circumstance. Create opportunities for visibility in the organization.

- Start each year with a new slate. Believe in your team and develop them.

- Be transparent in relationships with team.

- Respect the personal space and confidentiality of team members.

\subsection{Research Results: Leaders That Demonstrate Compassion Are Highly Valued (876 Responses)}

The feedback included significant responses focusing on empathy and compassion. Leaders are especially valued when they connect with how people react to disruptive events, and how people feel during tough times and personal tragedies. They want leaders who show compassion when there are disappointments. They respect leaders who are sensitive to people's feelings and thus choose their 
words, tone, and actions carefully. They want leaders who show empathy and provide support for team members struggling with personal problems (health, family problems, emotional issues). They also expect workload and attendance flexibility when going through tough personal times.

\section{Research Conclusions: Dominant Behaviors and Habits of Effective Leaders}

Extensive analysis of the research data not only revealed the importance of connection conversations, but it also revealed that much of what team members expect of leaders revolves around personal character and the willingness to put the needs of the team first. Based on the research, this writer developed an array of specific behaviors as a guide for leaders who want to stay engaged with their team to consistently achieve organization goals. They are, Nine Habits that Build Leadership Character, and Nine Key Connection Conversations.

\subsection{A Behavior Guide for Leaders to Follow: The Nine Habits That Build Leadership Character}

Character is an accumulation of beliefs, priorities, and habits that drive behavior. Here are the nine-character building habits based on the survey and interview feedback.

1) Connection Conversations. Have frequent connection conversations with team members (see 6.2).

2) Respect and Trust. Teach it, build it, protect it. Without it, you will never have a cohesive team.

3) Recognition. Give credit where credit is due. Recognize "good" behavior, not just exceptional behavior.

4) Development. Facilitate and coach individual and team development. Encourage growth.

5) Commitment. Commit to your team. Put team's needs first. Say what you mean, mean what you say.

6) Advocacy. Promote your team to others. Go to bat for them in every circumstance. You take the fall when things don't go right.

7) Compassion. There will be stormy days. Be there for whoever it is and insist your team be there too.

8) Confidentiality. Respect the personal property, space, and privacy rights of your team members.

9) Transparency. Maintain accessibility and visibility of information and business practices. Open, honest.

\subsection{A Behavior Guide for Leaders to Follow: The Nine Key Connection Conversations That Are Necessary in Every Organization}

Conversations make a difference. Based on the survey and interview feedback, here are nine types of conversations that will keep your team engaged, aimed in 
the right direction, and make your life as a leader easier.

1) Relationship connection conversation, 2) Role and expectations conversation, 3) Performance goals and alignment conversation, 4) Workflow and workload conversation, 5) Feedback and recognition conversation, 6) Stormy day support conversation, 7) Development and career aspirations conversation, 8) Checking-in conversation, 9) Disruption conversation.

Events will dictate the order of some of these conversations, others should be scheduled. Some will occur multiple times annually. Some of the nine conversations include leadership tools such as, the Three-point Performance Alignment and Coaching Tool, to facilitate a positive outcome.

\subsection{The Myth about Leading an Organization to Success}

It is a myth that you can "lead" your organization to success. It takes managing as well. To achieve organization success, you must "behave like a leader and operate like a manager."

\section{Conflicts of Interest}

The author declares no conflicts of interest regarding the publication of this paper.

\section{References}

Goodall, A., \& Baker, A. (2014). A Theory Exploring How Expert Leaders Influence Performance in Knowledge-Intensive Organizations. In Incentives and Performance: Governance of Research Organizations (Part 1, pp. 49-67). Springer.

Hersey, P., \& Blanchard, K. H. (1969). Management of Organizational Behavior: Utilizing Human Resources. New Jersey/Prentice Hall.

Lee, A., Willis, S., \& Tian, A. W. (2018). When Empowering Employees Works, and When It Doesn't. Harvard Business Review. https://hbr.org/2018/03/when-empowering-employees-works-and-when-it-doesnt

Westfall, C. (2019 Jun 20). Leadership Development Is a \$366 Billion Industry: Here’s Why Most Programs Don't Work. Forbes.com https://www.forbes.com/sites/chriswestfall/2019/06/20/leadership-development-why-m ost-programs-dont-work/ 